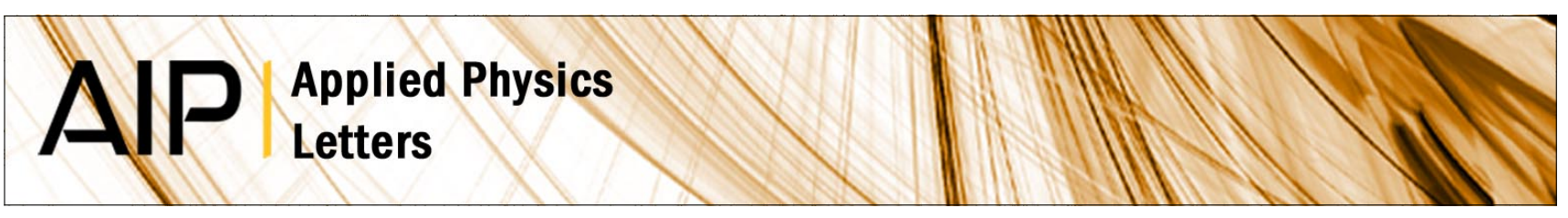

\title{
InGaN epilayer characterization by microfocused $x$-ray reciprocal space mapping
}

V. Kachkanov, I. P. Dolbnya, K. P. O’Donnell, R. W. Martin, P. R. Edwards et al.

Citation: Appl. Phys. Lett. 99, 181909 (2011); doi: 10.1063/1.3658619

View online: http://dx.doi.org/10.1063/1.3658619

View Table of Contents: http://apl.aip.org/resource/1/APPLAB/v99/i18

Published by the American Institute of Physics.

\section{Related Articles}

Fixed nitrogen atoms in the $\mathrm{SiO} / \mathrm{SiC}$ interface region and their direct relationship to interface trap density Appl. Phys. Lett. 99, 182111 (2011)

Polarity replication across m-plane GaN/ZnO interfaces

Appl. Phys. Lett. 99, 181910 (2011)

Temperature dependent photoluminescence of lateral polarity junctions of metal organic chemical vapor deposition grown GaN

J. Appl. Phys. 110, 093503 (2011)

Investigation of $\mathrm{Ge} 1-\mathrm{xSnx} / \mathrm{Ge}$ with high $\mathrm{Sn}$ composition grown at low-temperature

AlP Advances 1, 042118 (2011)

Mechanisms of suppressing secondary nucleation for low-power and low-temperature microwave plasma selfbias-enhanced growth of diamond films in argon diluted methane

AlP Advances 1, 042117 (2011)

\section{Additional information on Appl. Phys. Lett.}

Journal Homepage: http://apl.aip.org/

Journal Information: http://apl.aip.org/about/about_the_journal

Top downloads: http://apl.aip.org/features/most_downloaded

Information for Authors: http://apl.aip.org/authors

\section{ADVERTISEMENT}

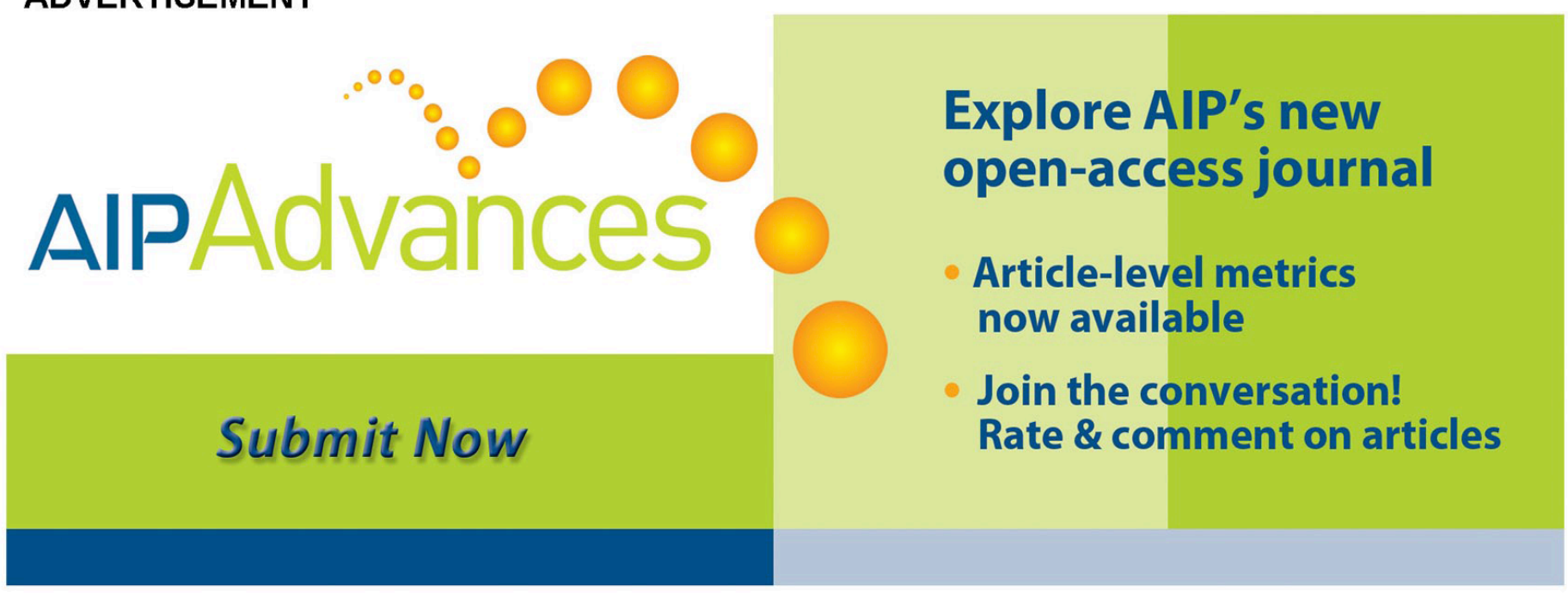




\title{
InGaN epilayer characterization by microfocused x-ray reciprocal space mapping
}

\author{
V. Kachkanov, ${ }^{1, a)}$ I. P. Dolbnya, ${ }^{1}$ K. P. O'Donnell, ${ }^{2}$ R. W. Martin, ${ }^{2}$ P. R. Edwards, ${ }^{2}$ \\ and S. Pereira ${ }^{3}$ \\ ${ }^{1}$ Diamond Light Source Ltd., Diamond House, Chilton, Didcot, Oxfordshire OX11 ODE, United Kingdom \\ ${ }^{2}$ Department of Physics, SUPA, University of Strathclyde, Glasgow, Scotland G4 ONG, United Kingdom \\ ${ }^{3}$ Department of Physics, CICECO, University of Aveiro, 3810-193 Aveiro, Portugal
}

(Received 8 July 2011; accepted 11 October 2011; published online 4 November 2011)

\begin{abstract}
We report the use of microfocused three-dimensional x-ray reciprocal space mapping to study InGaN epilayers with average $\mathrm{InN}$ content $\sim 20 \%-22 \%$. Analysis of the full volume of reciprocal space, while probing samples on the microscale with a focused x-ray beam, allowed us to gain valuable information about the nanostructure of InN-rich InGaN epilayers. It is found that "seed" InGaN mosaic nanocrystallites are twisted with respect to the ensemble average and strain-free. The initial stages of InGaN-on-GaN epitaxial growth, therefore, conform to the Volmer-Weber growth mechanism with "seeds" nucleated on strain fields generated by the $a$-type edge dislocations. (C) 2011 American Institute of Physics. [doi:10.1063/1.3658619]
\end{abstract}

The III-nitride semiconductors ( $\mathrm{GaN}, \mathrm{InN}, \mathrm{AlN}$, and their alloys) have become a subject of intense research in the past 15 years due to the unique physical properties of these materials, which include a wide direct bandgap, remarkable mechanical strength and high melting temperatures, as well as their huge commercial utility. The technological breakthrough in the epitaxial growth of InGaN structures ${ }^{1}$ has revolutionized the optoelectronic industry, leading recently to robust and compact all-solid state light sources covering the broad spectral range from infra-red to ultraviolet. However, further advances in nitride technology, for example nitride laser diodes emitting in the green and red spectral regions, require a deeper understanding of the microstructure and nanostructure of $\operatorname{In}_{x} \mathrm{Ga}_{1-x} \mathrm{~N}$ alloy films.

$\mathrm{X}$-ray reciprocal space mapping (RSM) is a powerful tool to explore the structure of materials. However, RSMs are usually measured in two dimensions (2D) ignoring the third dimension of diffraction space volume. The idea of full three-dimensional (3D) diffraction space mapping to obtain information on the 3D structure of materials was first introduced by Fewster $e t$ al. $^{2}$ In this letter, we report the study of InGaN epilayers by 3D RSM while probing the material with a microfocused x-ray beam.

The samples studied were nominally undoped wurtzite $\mathrm{In}_{x} \mathrm{Ga}_{1-x} \mathrm{~N}$ layers, grown by metalorganic chemical vapor deposition (MOCVD) on $\mathrm{GaN} / \mathrm{Al}_{2} \mathrm{O}_{3}$ (0001) substrates. The nominal thickness of the InGaN layers was $250 \mathrm{~nm}$, whereas the GaN buffers were $\sim 2 \mu \mathrm{m}$ thick. The samples were grown at the University of Gent. ${ }^{3}$

The microdiffraction experiments were carried out on beamline B16 at the Diamond Light Source, UK. The synchrotron storage ring operated at $3 \mathrm{GeV}$ with a current of $200 \mathrm{~mA}$. The x-ray energy, selected by a Si(111) monochromator, was fixed at $12400 \mathrm{eV}(1 \AA)$. The $\mathrm{x}$-ray beam was focused by beryllium compound refractive lenses (CRLs). A

\footnotetext{
${ }^{\text {a) }}$ Author to whom correspondence should be addressed. Electronic mail: slava.kachkanov@diamond.ac.uk.
}

set of 63 lenses was used to focus the x-ray beam down to a spot size with full widths at half maximum (FWHM) of 3.2 (horizontal) $\mu \mathrm{m} \times 1.6 \mu \mathrm{m}$ (vertical). The focal length was $750 \mathrm{~mm}$ and the effective aperture of the CRLs was calculated to be $D_{\text {eff }} \approx 0.6 \mathrm{~mm}$ resulting in horizontal and vertical incident beam divergences of $\sim 0.8 \mathrm{mrad}$. The demagnification factor of the lens system was estimated to be $\sim 58$. The required sample rotations and translations were performed using a high precision 5-circle Huber diffractometer with 0.1 millidegree resolution and a Huber XYZ sample stage. A Pilatus 100k detector with pixel size of $0.172 \times 0.172 \mathrm{~mm}$ was used to record the diffracted $\mathrm{x}$-rays from the sample. The distance between detector and sample was $883 \mathrm{~mm}$.

The measurements of the full 3D shape of the (1013) reciprocal lattice point (RLP) were done in skew symmetric geometry by changing the incident angle $\omega$ to the diffracting plane and recording the $2 \mathrm{D}$ diffraction pattern. The reciprocal space subtended by the detector was converted into scattering vector components in the reference frame of the GaN substrate with $\mathrm{Q}_{\mathrm{x}}$ lying along [120], $\mathrm{Q}_{\mathrm{y}}$ along [100], and $\mathrm{Q}_{\mathrm{z}}$ along [001] directions. The effective $\mathrm{x}$-ray beam spot on the sample was $\sim 4 \times 5 \mu \mathrm{m}$ FWHM for the (1013) reflection.

Figures 1(a) and 1(b) show projections of the (1013) RLP onto the $\mathrm{Q}_{\mathrm{y}}-\mathrm{Q}_{\mathrm{z}}$ plane for samples $\mathrm{A}$ and $\mathrm{B}$ measured at $\omega=19.424^{\circ}$ and $\omega=19.357^{\circ}$, respectively. The (1013) RLP corresponding to the InGaN epilayer is broadened due to both compositional gradient and strain. Reciprocal space coordinates $\mathrm{Q}_{\mathrm{y}}$ and $\mathrm{Q}_{\mathrm{z}}$ of the InGaN RLP are directly related to the lattice constants $a$ and $c$, respectively. Knowing the lattice parameters, it is possible to estimate the $\mathrm{InN}$ content $x$ by finding physically acceptable solutions of the two dimensional Poisson ratio equation. ${ }^{4}$ The following input parameters required for the solution of Poisson equation were used: lattice constants $c_{\mathrm{GaN}}=5.1850 \AA, a_{\mathrm{GaN}}=3.1892 \AA$ for $\mathrm{GaN}$ (Ref. 5) and $c_{\mathrm{InN}}=5.7033 \AA, a_{\mathrm{InN}}=3.5378 \AA$ for InN, ${ }^{6}$ and elastic constants ${ }^{7} c_{13}=103 \mathrm{Gpa}$ and $c_{33}=405 \mathrm{Gpa}$ for $\mathrm{GaN}$ and $c_{13}=92 \mathrm{Gpa}$ and $c_{33}=224 \mathrm{Gpa}$ for InN. Sample A exhibits a compositional gradient: the $\mathrm{InN}$ fraction estimated 
(a)
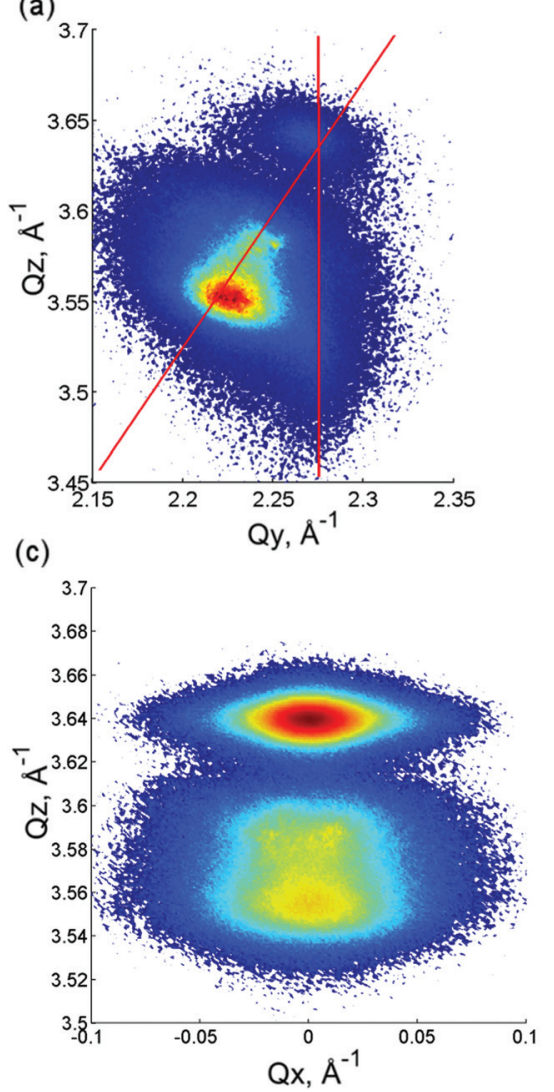

(b)
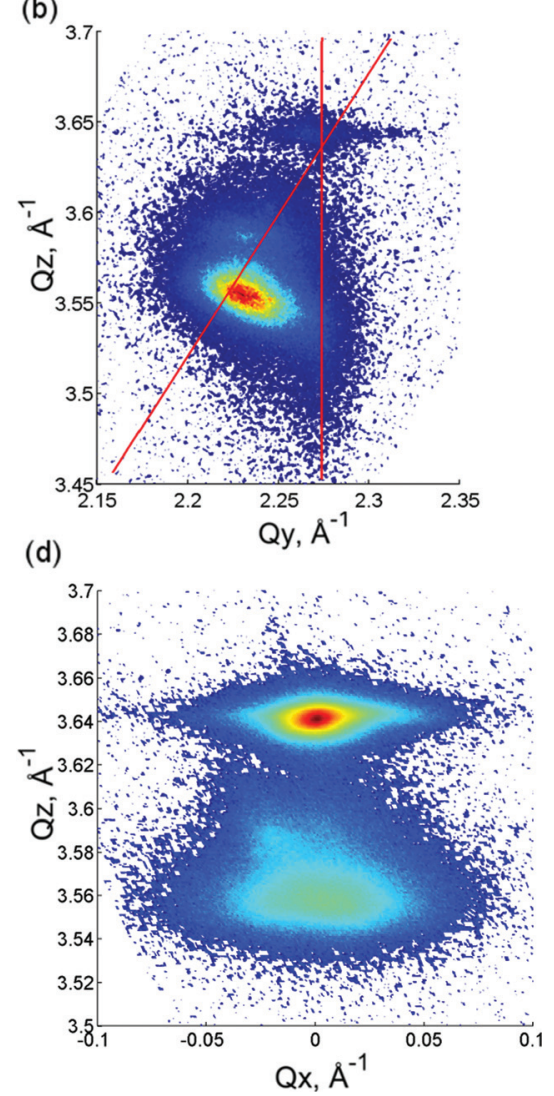

FIG. 1. (Color) (a) and (b) show projections of the (1013) RLP onto the $\mathrm{Q}_{\mathrm{y}}-\mathrm{Q}_{\mathrm{z}}$ plane for sample $\mathrm{A}$ and sample B measured for $\omega=19.424^{\circ}$ and $\omega=19.357^{\circ}$, respectively, (c) and (d) are projections of the (1013) RLP on the $Q_{x}-Q_{z}$ plane for the same samples. The inclined and vertical red lines in (a) and (b) indicate lattice constants for relaxed InGaN alloys and $a$ lattice contstant (3.189 $\AA$ ) for unstrained GaN. The "tails" of (1013) RLPs correspond to the "seed" InGaN. from the breadth of the RLP varies from $12 \%$ up to $25 \%$. The strain state of InGaN epilayer in this sample varies from fully relaxed to pseudomorphic to the substrate. The center of mass (COM) of the (1013) RLP corresponds to an InN content of $22 \%$ under slight compressive strain. Interestingly, the "seed" InGaN with $12 \%$ of InN is completely relaxed. For sample B, the InN content ranges from $10 \%$ to $24 \%$ and the strain state changes from relaxed to pseudomorphic. Again, the COM of the RLP corresponds to $20 \% \mathrm{InN}$ under compressive strain and the "seed," with $10 \%$ of $\operatorname{InN}$, is completely relaxed. A spatial scan across the sample B, monitoring the position of the COM for the (1013) RLP and calculating the InN content at each point, revealed the presence of a weak lateral composition gradient as shown in Figure 2. Microfocusing allows us to disentangle lateral and vertical composition gradients on the length scales defined by the effective size of the $x$-ray beam. Figure 2 shows that the lateral composition variation is macroscopic and that it is much weaker than the vertical composition variation for a particular point on the sample. Figs. 1(c) and 1(d) show the projection of the (1013) RLP on to the $Q_{x}-Q_{z}$ plane for samples A and B, respectively. What is observed here is that the "seeds" of composition gradient in both samples are inclined with respect to the COM of the InGaN RLP. In the case of sample A, there are two somewhat diffuse "seed" tails inclined by $0.40^{\circ}$ and $0.13^{\circ}$, respectively. In the case of sample B, there is only one sharp "seed" inclined by an angle of $0.19^{\circ}$.
Heteroepitaxial films with large lattice mismatch to their substrates and exhibiting a high density of dislocations are best described as a collection of mosaic crystals. ${ }^{8}$ The layer is assumed to consist of single crystallites, called mosaic blocks, tilted and twisted with respect to each other. Taking into account the geometry of the present experiments, a tilt $\theta$ along the [120] direction corresponds mainly to a twist $\varphi$

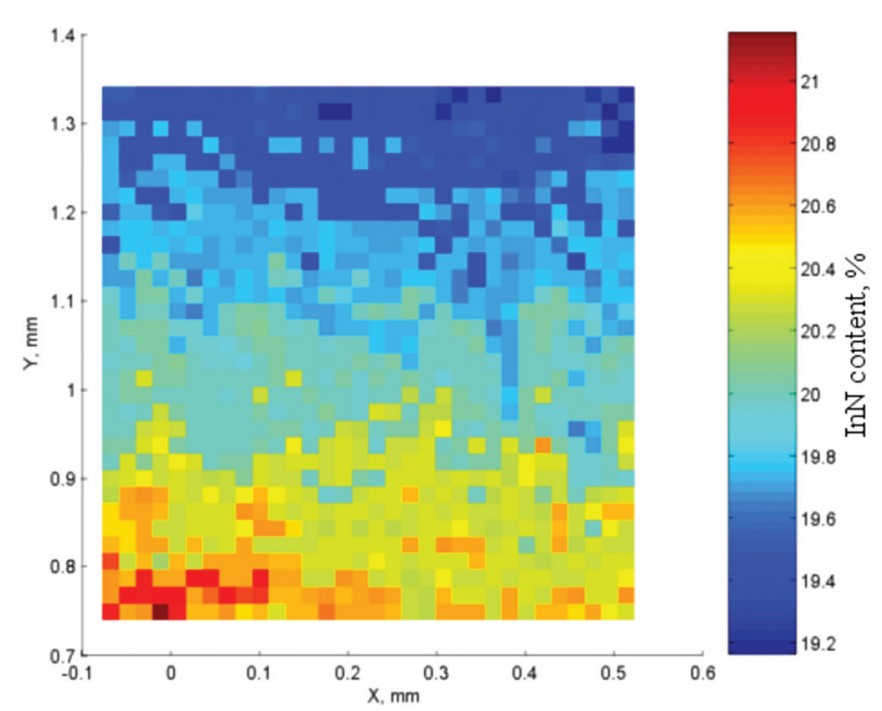

FIG. 2. (Color) Map of InN content $x$ for $\operatorname{In}_{x} \mathrm{Ga}_{1-x} \mathrm{~N}$ sample B measured at $\omega=19.220^{\circ}$. 


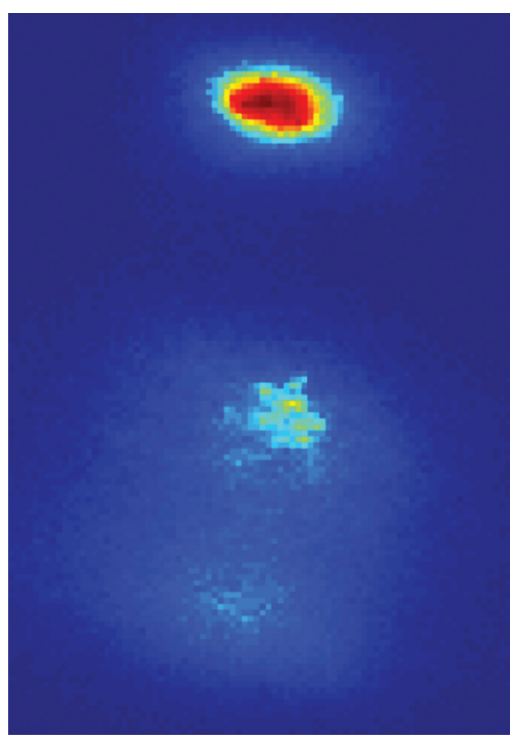

FIG. 3. (Color) The x-ray diffraction intensity speckle pattern for sample A observed during spatial scan. Note that the image is not transformed to reciprocal space.

with respect to the [001] direction through the following relation

$$
\tan \varphi=-\frac{1}{\sin \chi} \tan \theta
$$

where $\chi$ is the angle between the (1013) and (0001) planes. Thus, the observed tilting of the "seed" corresponds to twists by $0.75^{\circ}$ clockwise and $0.37^{\circ}$ anticlockwise around the [001] axis for sample A. For sample B "seed," the crystallites are twisted by $0.35^{\circ}$ clockwise around the [001] axis.

An unusual speckle pattern of diffracted x-ray intensity is observed for the InGaN "seed" in both samples. An example is shown in Figure 3. The appearance of the speckles is due to partial coherence of the incident $\mathrm{x}$-ray beam-the coherent sum of the scattering from a random array of domains results in a speckle pattern modulating a diffuse peak. ${ }^{9}$ The significance of the speckle pattern is that it indicates that the size of the crystallites in the "seeds" is less than the transverse X-ray coherence length, which for B16 beamline is estimated to be $\sim 250 \mathrm{~nm}$ after demagnification by CRLs and change of beam footprint for (1013) reflection.

In summary, 3D RSM with a microfocused $\mathrm{x}$-ray beam reveals a complex structure of InGaN epilayers on the micro- scale and smaller. Strain-free and twisted InGaN nanocrystallites, less than $\sim 250 \mathrm{~nm}$ in lateral size, are observed at the lower end of composition gradient. Formation of strain-free InGaN islands during the initial phases of growth was also observed by in-situ 2D RSM. ${ }^{10}$ Most importantly, it was observed $^{11}$ that structural and compositional disorder increases with growth time thus supporting suggestion that the islands observed in our $e x$-situ experiments correspond to the beginning of epitaxial growth. The twist of InGaN nanocrystallites is caused by the twist of the underlying GaN mosaic blocks which in the case of III-nitrides was found to be related to $a$-type edge dislocations. ${ }^{11}$ The average size of the mosaic blocks in the GaN substrate, estimated from the FWHM of the diffraction peak along $\mathrm{Q}_{\mathrm{y}},{ }^{12}$ is $\sim 50 \mathrm{~nm}$ and $\sim 100 \mathrm{~nm}$ for samples A and B, respectively. The lattice mismatch between InGaN and $\mathrm{GaN}$ may be relieved by the microstrain associated with $a$-type edge dislocation. Thus, the initial stages of InGaN epitaxial growth correspond to Volmer-Weber growth with the nucleation of "seed" islands on strain fields generated by the $a$-type edge dislocations. As more of the substrate surface is covered, the structural disorder increases, as indicated by the breadth of the InGaN RLP.

The authors are grateful to Wim van der Stricht for providing the samples used in this study. Dr. K. J. Sawhney is acknowleged for his help during experiments. S. Pereira acknowledges funding from FCT (Portugal) through project Ref. PTDC/CTM/101453/2008. Diamond Light Source is acknowledged for providing beamtime.

${ }^{1}$ S. Nakamura, M. Senoh, and T. Mukai, Jpn. J. Appl. Phys. 32, L8 (1993). ${ }^{2}$ P. F. Fewster and N. L. Andrew, J. Phys. D: Appl. Phys. 28, A97 (1995).

${ }^{3}$ W. Van der Stricht, Ph.D. thesis, University of Gent, 1999.

${ }^{4}$ S. Pereira, M. R. Correia, E. Pereira, K. P. O'Donnell, E. Alves, A. D. Sequeira, and N. Franco, Appl. Phys. Lett. 79, 1432 (2001).

${ }^{5}$ T. Detchprohm, K. Hiramatsu, K. Itoh, and I. Akasaki, Jpn. J. Appl. Phys., Part 2 31, L1454 (1992).

${ }^{6}$ W. Paszkowicz, Powder Diffr. 14, 258 (1999).

${ }^{7}$ A. F. Wright, J. Appl. Phys. 82, 2833 (1997).

${ }^{8}$ M. A. Moram and M. E. Vickers, Rep. Prog. Phys. 72, 036502 (2009).

${ }^{9}$ M. Sutton, S. G. J. Mocherie, T. Greytak, S. E. Nagler, L. E. Bermans, G. A. Held, and G. B. Stephenson, Nature 352, 608 (1991).

${ }^{10}$ M.-I. Richard, M. J. Highland, T. T. Fister, A. Munkholm, J. Mei, S. K. Streiffer, C. Thompson, P. H. Fuoss, and G. B. Stephenson, Appl. Phys. Lett. 96, 051911 (2010).

${ }^{11}$ T. Metzger, R. Hopler, E. Born, O. Ambacher, M. Stutzmann, R. Stommer, M. Schuster, H. Gobel, S. Christiansen, M. Albrecht, and H. P. Strunk, Philos. Mag. A 77, 1013 (1998).

${ }^{12}$ P. F. Fewster, X-ray Scattering from Semiconductors (Imperial College Press, London, 2000). 